\title{
GENCO Optimal Bidding Strategy and Profit Based Unit Commitment using Evolutionary Particle Swarm Optimization Illustrating the Effect of GENCO Market Power
}

\author{
Adline K. Bikeri ${ }^{1}$, Christopher M. Muriithi ${ }^{2}$, and Peter K. Kihato ${ }^{3}$ \\ ${ }^{1,3}$ School of Electrical, Electronic, and Information Engineering, Jomo Kenyatta University of Agriculture \& Technology, \\ Kenya \\ ${ }^{2}$ Department of Electrical and Power Engineering, Technical University of Kenya, Kenya
}

\begin{tabular}{l}
\hline \hline Article Info \\
\hline Article history: \\
Received October 27, 2017 \\
Revised April 10, 2018 \\
Accepted: May 3, 2018
\end{tabular}

Keyword:

Profit Based Unit Commitment EPSO

PSO

GENCO Market Power

Deregulated Electricity Market

\begin{abstract}
In deregulated electricity markets, generation companies (GENCOs) make unit commitment (UC) decisions based on a profit maximization objective in what is termed profit based unit commitment (PBUC). PBUC is done for the GENCOs demand which is a summation of its bilateral demand and allocations from the spot energy market. While the bilateral demand is known, allocations from the spot energy market depend on the GENCOs bidding strategy. A GENCO thus requires an optimal bidding strategy (OBS) which when combined with a PBUC approach would maximize operating profits. In this paper, a solution of the combined OBS-PBUC problem is presented. An evolutionary particle swarm optimization (EPSO) algorithm is implemented for solving the optimization problem. Simulation results carried out for a test power system with GENCOs of differing market strengths show that the optimal bidding strategy depends on the GENCOs market power. Larger GENCOs with significant market power would typically bid higher to raise market clearing prices while smaller GENCOs would typically bid lower to capture a larger portion of the spot market demand. It is also illustrated that the proposed EPSO algorithm has a better performance in terms of solution quality than the classical PSO algorithm.
\end{abstract}

\section{Corresponding Author:}

Adline K. Bikeri

School of Electrical, Electronic, and Information Engineering,

Jomo Kenyatta University of Agriculture \& Technology

P.O. Box 62000-00200, Nairobi, Kenya.

Email: adlinebikeri@gmail.com

\section{INTRODUCTION}

Traditionally, one of the most important aspects of power system operation is the prior scheduling of generating units also referred to as unit commitment (UC) $[1,2,3]$. UC schedules are usually determined on a week-ahead, day-ahead, or even just a few hours before operation. Prior scheduling of generating units increases efficiency by ensuring a least-cost operating regime while keeping system reliability. In traditional, regulated environments, UC is done from a "least-cost" point-of-view [4]. While in the very short-term rule-of-thumb methods can be applied, power utilities usually invest in system optimization software as the extra cost resulting from non-optimal operation could be significant.

UC in deregulated markets take a different approach. Unlike the regulated environment, the independent system operator (ISO) who is in charge of ensuring that demand is met does not own or operate any generating units $[5,6]$. The ISO receives supply bids from the various generation companies (GENCOs) in the system and then allocates the demand to these GENCOs based on a cheapest-first method. The GENCOs in the system thus have to compete for a proportion of the demand so as to make money. In some systems, apart from the allocations 
in the ISO operated energy market (spot market), GENCOs may independently negotiate bilateral supply contracts with consumers though they may have to use the ISO's transmission network to deliver agreed power [6].

Each individual GENCO still has to draw up its own generations schedules especially because operational constraints on generating units such as minimum-up time or minimum-down times could significantly eat into a GENCOs profit if not properly considered in the operational planning stage. A GENCO's UC schedule is based on expected own demand from both the spot and bilateral energy markets with the aim of maximizing profits [7]. Thus, in deregulated markets, UC is done from a profit maximization point of view hence the term profit based unit commitment (PBUC) [8]. However, the allocation from the spot energy market depends largely on a GENCO's bidding strategy [9]. The GENCO may either lower its bids aiming to increase its allocation or raise its bids so as to raise the electricity prices which means that the GENCO's own demand and hence its UC schedule depends significantly on its adopted bidding strategy.

An important determinant of a GENCO's bidding strategy in the spot market is its market power i.e. the GENCO's ability to alter the market price and allocations in the market. A GENCO whose actions cannot affect the market equilibrium is referred to a price taker and conversely, a GENCO whose actions significantly affect the market is referred to as a price maker. Electricity markets usually assume an oligopolistic structure characterized by several price takers and one or two price makers; usually large companies that are offshoots of the previous regional or national utilities prior to deregulation [10]. Since the GENCO's market power can influence the market price, it is a significant consideration in the determination of an optimal bidding strategy (OBS) and hence the solution of the PBUC problem.

Several approaches for the solution of the PBUC problem have been proposed in literature. Classical mathematical methods such as Priority Listing (PL), Dynamic Programming (DP), Branch and Bound, Mixed Integer Programming (MIP), and Lagrangian Relaxation have been proposed in [11, 12]. Newer, heuristic based methods such as Genetic Algorithm (GA), Ant colony optimization (ACO), Particle swarm optimization (PSO), and Artificial bee colony (ABC) have been proposed in [13, 14, 15]. Hybrid methods that combine two or more solution approaches have also been proposed [16, 17].

Heuristic based methods provide the advantages of a more thorough search of the solution space and being less prone to getting stuck at local optimum solutions. Also, there is a reduced mathematical computation burden since these method don't require the computation of gradients which may be quite difficult in certain instances. The evolutionary particle swarm optimization (EPSO) algorithm [18, 19, 20], which combines the classical PSO algorithm with evolutionary programming (EP) concepts, is one of the most promising algorithms for the solution of various power system operation optimization problems. It has been shown that EPSO has better convergence characteristics than the conventional PSO and usually gives better results. In this paper, an EPSO algorithm based solution methodology is proposed to solve the combined optimal bidding strategy and PBUC problem. The application of the proposed solution methodology is illustrated for several GENCOs of differing sizes operating in a test power system.

The rest of the paper is organized as follows. Section 2. introduces the concept of GENCO bidding strategies in electricity markets with an illustration of how a GENCO can set its bidding strategy to increase its profits. Section 3. introduces the general EPSO algorithm. The problem formulation is given in section 4. and the proposed solution algorithm in section 5.. Numerical simulations are presented in section 6 . while conclusions are given in section 7 ..

\section{GENCO BIDDING STRATEGIES IN ELECTRICITY MARKETS}

In deregulated electricity markets, electric energy is sold either through bilateral agreements between GENCOs and consumers or through an electricity pool operated by an independent system operator i.e. the electricity spot market [21]. In the case of the bilateral market, the buyer and seller agree on a transaction price from which the GENCO meets all costs for transmission, distribution, and other ancillary services. The electricity pool is however operated by an independent system operator ISO who receives and aggregates hourly energy supply bids from GENCOs and hourly demand bids from consumers after which a market clearing price (MCP) is determined [6]. The GENCOs are allocated portions of the demand based on a cheapest-bid first while ensuring system reliability and security. The MCP is defined as the cost of supplying the last MW of demand and all GENCOs who receive load allocations for the given hour are paid at this price irrespective of their bids.

Each GENCO will combine the bilateral demand with the allocation from the spot market as its own demand and from this data draw up a UC schedule based on a profit maximization objective. Since the spot market allocation is based largely on the GENCO's bid and those of its competitors, the GENCO bid decisions significantly affect its allocation and hence its profits. Should a GENCO have enough influence, it could affect the

IJECE Vol. 8, No. 4, August 2018: 1997 - 2013 
market clearing price and consequently its profits. The magnitude of this influence defines the GENCO's market power. Under perfect competition, so as to maximize its profits, a GENCO should bid at its marginal cost (cost of supplying an extra MW of electricity) [9]. However, depending on the market environment, the GENCO could increase its profits in one of two ways:

- The GENCO could lower its bid (bid low) thereby potentially increasing its allocation in the spot market though this could reduce the MCP. Bidding low is justified if the reduced revenue due to the lower prices is covered by the increased revenue due to a larger allocation.

- The could raise its bid (bid high) thereby potentially reducing its allocation in the spot market but increasing the MCP. This is justified if the increased revenue due to the higher prices cover the revenue lost due to a smaller allocation.

A minimal example to illustrate the spot market dynamics follows next.

The GENCO marginal cost curve forms the basis of its bidding strategy. The marginal cost curve is a plot of the incremental cost of power generation against the total power output for a GENCO. Mathematically, $M C_{i}-$ the marginal cost curve for GENCO $i$ is given by:

$$
M C_{i}=\frac{\partial C_{T i}}{\partial P_{T i}}
$$

where $C_{T i}$ is the total operating cost of GENCO $i$ when supplying a total of $P_{T i}$ MW. Assuming a quadratic cost curve for GENCO costs, $C_{T i}$ is given by:

$$
C_{T i}=\sum_{j=1}^{N}\left(a_{i j}+b_{i j} P_{i j}+c_{i j} P_{i j}^{2}\right),
$$

and

$$
P_{T i}=\sum_{j=1}^{N} P_{i j} .
$$

In (2) and (3) $a_{i j}, b_{i j}$, and $c_{i j}$ are the coefficients of the quadratic cost curves for unit $j$ operated by GENCO $i$ while $P_{i j}$ is the output of unit $j$ operated by GENCO $i$.

Consider two GENCOs each owning one generating unit with cost characteristics shown in Table 1. The marginal cost curves for the two GENCOs are plotted in Figure 1(a) showing that GENCO G1 has the cheaper generating unit of the two GENCOs. If each GENCO submits its marginal cost curve as its supply curve, the combined system supply curve will be as shown in Figure 1(b). Assuming a nominal system demand of 200 MW with a linear demand curve as shown in Figure 1(b), the market equilibrium will then be the point at which the two curves intersect. When read from Figure $1(\mathrm{~b})$ this point is $\left(P_{d}=200 \mathrm{MW}, \mathrm{MCP}=\$ 30.78 / \mathrm{MWh}\right)$. When extrapolated to the supply curves of the two GENCOs, G1 and G2 will supply $144.4 \mathrm{MW}$ and $55.6 \mathrm{MW}$ respectively.

Table 1. Example GENCO cost characteristics

\begin{tabular}{cccc}
\hline GENCO & $P_{i 1}^{\min }$ & $P_{i 1}^{\max }$ & Cost Equation $C_{T i}\left(P_{i j}\right)$ \\
\hline G1 & 0 & 300 & $25 P_{11}+0.020 P_{11}^{2}$ \\
G2 & 0 & 150 & $28 P_{21}+0.025 P_{21}^{2}$ \\
\hline
\end{tabular}

Now, consider a case where GENCO G1 submits bids where the gradient of its marginal cost curve is multiplied by a factor $\mu_{1}$. Its bid curve, $B C_{1}$ is then given by:

$$
B C_{1}=b_{11}+\mu_{1} \cdot 2 c_{11} P_{11}=25+0.04 \mu_{1} P_{11}
$$

A value of $\mu_{1}>1$ raises the bid curve above the nominal meaning that the GENCO bids high while a value of $\mu_{1}<1$ means that the GENCO bids low. The effect of $\mu_{1}$ on the MCP and the GENCO allocations is illustrated in Figure 2 for values of $\mu_{1}=0.8$, and $\mu_{1}=1.2$. The results are summarized in Table 2 showing that as $\mu_{1}$ increases, the MCP increases, GENCO G1's allocation reduces (as does its revenue and costs) but its profit increases. 


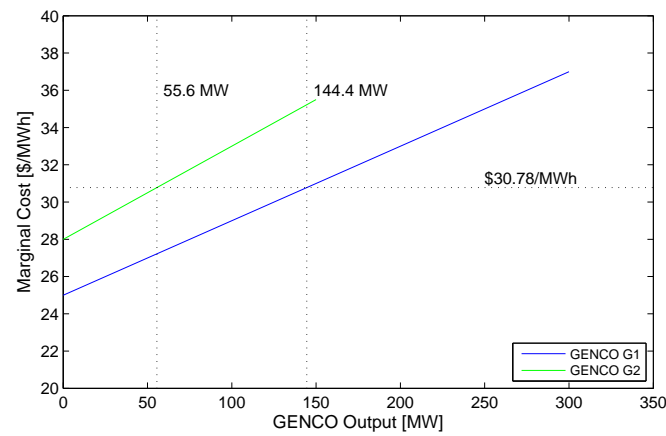

(a)

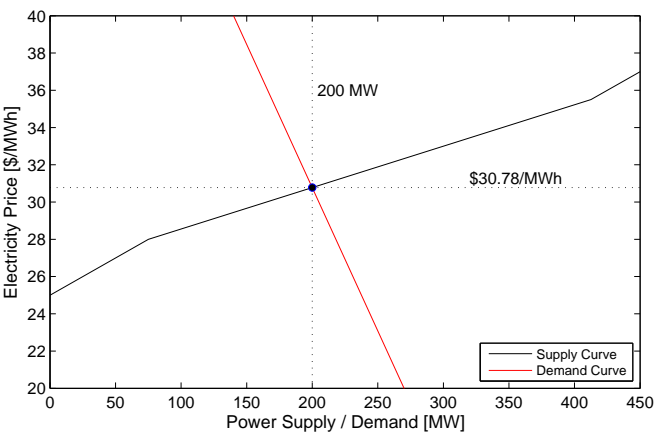

(b)

Figure 1. (a) Marginal cost curves for two GENCOs and (b) market equilibrium obtained from the intersection of the aggregated supply curve and the system demand curve.

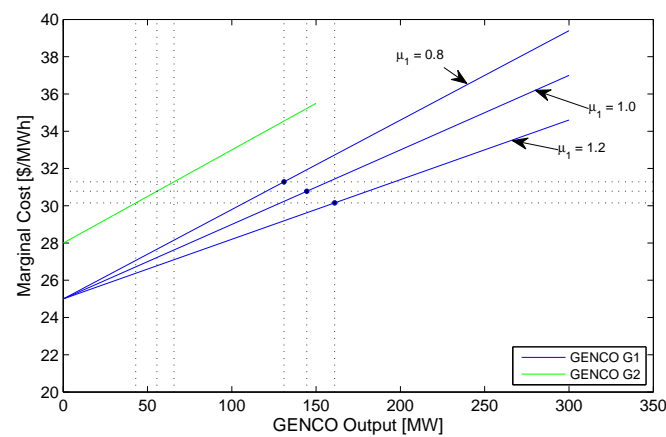

(a)

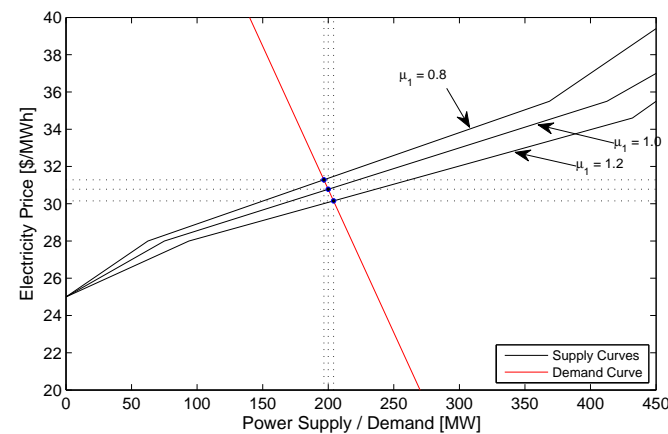

(b)

Figure 2. Illustration of the effect of GENCO G1's bid strategy on (a) the demand allocations and (b) the MCP.

Table 2. Effect of GENCO bidding strategy on spot market prices, allocations, revenues, costs, and profits

\begin{tabular}{cccccc}
\hline$\mu_{1}$ & $\begin{array}{c}\text { MCP } \\
{[\$ / \mathrm{MWh}]}\end{array}$ & $\begin{array}{c}P_{1} \\
{[\mathrm{MW}]}\end{array}$ & $\begin{array}{c}\text { Revenue } \\
{[\$ / \mathrm{h}]}\end{array}$ & $\begin{array}{c}\text { Cost } \\
{[\$ / \mathrm{h}]}\end{array}$ & $\begin{array}{c}\text { Profit } \\
{[\$ / \mathrm{h}]}\end{array}$ \\
\hline 0.8 & 30.15 & 161.01 & $4,854.98$ & $4,543.87$ & 311.11 \\
1.0 & 30.78 & 144.44 & $4,445.68$ & $4,028.40$ & 417.28 \\
1.2 & 31.29 & 130.97 & $4,097.48$ & $3,617.21$ & 480.27 \\
\hline
\end{tabular}

A plot of the GENCO profit against the value of $\mu_{i}$ for the two GENCOs acting individually is illustrated in Figure 3 which shows that the two GENCOs achieve maximum profits at different values of $\mu_{i}\left(\mu_{1}=1.9\right.$ and $\mu_{2}=0.6$ ). These results show that the larger GENCO G1 should bid high to increase its profits while conversely, the smaller GENCO G2 should bid low to increase its profits.

\section{EVOLUTIONARY PARTICLE SWARM OPTIMIZATION}

Evolutionary particle swarm optimization (EPSO) is a heuristic optimization algorithm based on a combination of the evolutionary programming (EP) and particle swarm optimization (PSO) concepts [18, 19, 22]. As with the classical PSO algorithm [23], candidate solutions (particles) are moved around the solution space in search of the best possible solution. Each particle defines a position in the solution space and during successive iterations, the particles are moved towards the best solutions discovered at the given point in the solution process. The EPSO particle movement rule used in updating the particle position is similar to the PSO particle update equation in that a particle moves towards its own personal best solution that it achieved so far ( $p B e s t)$, as well as towards the global best $(g B e s t)$ solution which is best among the best solutions achieved so far by all particles present in the 


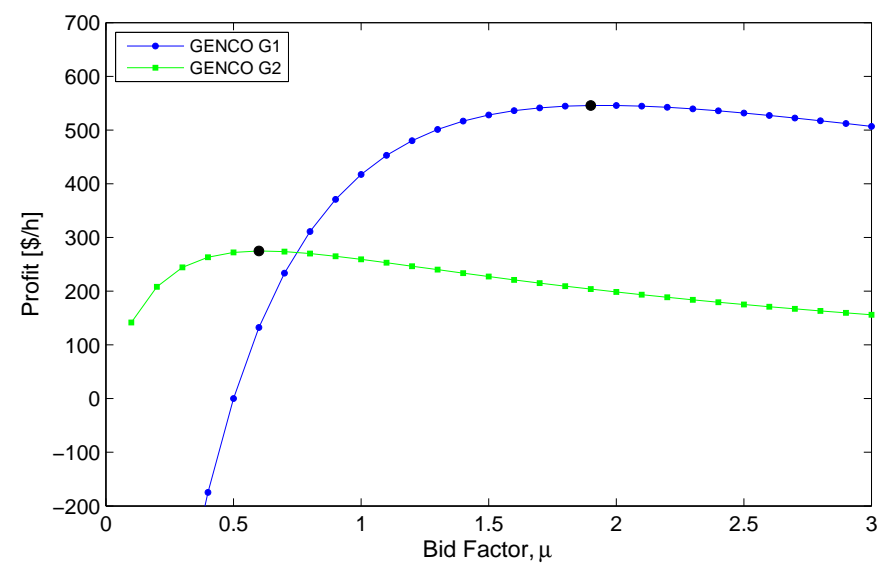

population. One important difference in the EPSE algorithm is that the $g B$ esteresition is "disturbed" hence the particles don't just aim for the already found $g B e s t$ position but rather for the region around the $g B e s t$ position which may actually be better than the already found $g B e s t$ [18].

One of the main challenges of the classical PSO algorithm is parameter tuning i.e. the determination of the best algorithm parameters to give the best solution. The EPSO algorithm addresses this challenge by progressively "mutating" the weight parameters with successive iterations. Thus, as the algorithm progresses, the weight parameters also evolve towards the best values. The basic structure of EPSO as originally explained in [18] carries out the following processes at each iteration:

- REPLICATION - each particle is replicated a number of times.

- MUTATION - each particle has its weights mutated.

- REPRODUCTION - each particle (original and replicas) generates an offspring according to the particle movement rule using the mutated weights.

- EVALUATION - each offspring has its fitness evaluated.

- SELECTION - the best particles between the original set and the mutated set survive based on a stochastic tournament to form a new generation.

After a certain pre-set number of iterations (generations), the particle with the global best solution is stored as the optimal solution. Incorporation of the Darwinistic characteristics of mutation and selection allows the EPSO algorithm to take advantage of the faster convergence characteristics of Evolutionary Programming (EP) strategies [19].

\section{PROBLEM FORMULATION}

Under the deregulated environment each individual GENCO seeks to capture a significant proportion of the spot electricity market and then determine a generation schedule that maximizes its profit based on expected prices at each scheduling period. If the GENCO can significantly affect the electricity price at a given hour, then the GENCO can set up its bid to drive up profits at the specified hour. The GENCO's decision is then two-fold: (1) how to set up its bidding strategy either to capture a larger portion of the spot market or to drive up the electricity price, and (2) how to schedule the generating units to maximize its profit given the expected prices. This optimization problem is formulated here as an optimal bidding strategy - profit based unit commitment (OBSPBUC) problem. Revenues from both the day-ahead spot energy and reserve markets and the GENCO's bilateral contract commitments are considered. The objective function and the operational constraints are explained in the following subsections.

\subsection{Objective Function}

Profit $(P F)$ is defined as the difference between revenue $(R V)$ obtained from sale of energy and reserve and the total operating cost $(T C)$ of the GENCO. The objective function is thus given as:

$$
\text { Maximize } \quad P F=R V-T C \text {. }
$$




\subsubsection{GENCO Revenue}

In (5), $R V$ is given by:

$$
R V=\sum_{h=1}^{H}\left(R V p^{h}+R V r^{h}\right),
$$

where $R V p^{h}$ and $R V r^{h}$ are the revenues from the energy market and the reserve market at hour $h$ respectively. $H$ is the number of hours in the scheduling horizon. $R V p^{h}$ is calculated as:

$$
R V p^{h}=\alpha_{s}^{h} P_{s}^{h}+\alpha_{b}^{h} P_{b}^{h}+\kappa\left(\alpha_{s}^{h}-\alpha_{b}^{h}\right) P_{b}^{h},
$$

where $\alpha_{s}^{h}$ and $\alpha_{b}^{h}$ are the energy prices at the spot market and bilateral market respectively at hour $h, P_{s}^{h}$ and $P_{b}^{h}$ are the power supplied to the spot market and bilateral market respectively at hour $h$, and $\kappa$ is a contract of differences factor [24]. The first term in (7) represents revenue from the energy sold at the spot market, the second term represents revenue from bilateral contracts, while the third term represents revenue from contracts of differences. Contracts of differences are usually included in bilateral contracts to compensate suppliers and consumers for differences between the bilaterally agreed prices and the prevailing market price [24].

Revenue from reserve sales $R V r^{h}$ is given as:

$$
R V r^{h}=\alpha_{r}^{h} \sum_{j=1}^{N}\left(P_{j}^{\max }-P_{j}^{h}\right),
$$

where $\alpha_{r}^{h}$ is price of reserve capacity at hour $h, P_{j}^{\max }$ is the maximum capacity of unit $j$, and $P_{j}^{h}$ is the output of unit $j$ at hour $h . N$ is the total number of generating units. In (8), the same price is assumed for both spinning and non-spinning reserve. If the pricing is different, the equation could be split to have two terms accounting for each type of reserve.

\subsubsection{GENCO Costs}

Total cost $T C$ is a sum of generator fuel costs $(F C)$ and start up costs $(S U C)$ for all $N$ units over the entire scheduling period of $H$ hours given as:

$$
T C=\sum_{h=1}^{H} \sum_{j=1}^{N}\left(F C_{j}^{h}+S U C_{j}^{h}\right),
$$

where

$$
F C_{j}^{h}=a_{j}+b_{j} P_{j}^{h}+c_{j}\left(P_{j}^{h}\right)^{2},
$$

and

$$
S U C_{j}^{h}=\gamma_{j}\left(1-U_{j}^{h-1}\right) U_{j}^{h}
$$

where

$$
\gamma_{j}=\left\{\begin{array}{ll}
C S C_{j} & \text { if } \sum_{t=h-C S h r_{j}}^{h} U_{j}^{t} \geq C S h r_{j} \\
H S C_{j} & \text { if } \sum_{t=h-C S h r_{j}}^{h} U_{j}^{t}<C S h r_{j}
\end{array} .\right.
$$

In (11) and (12), $U_{j}^{h}$ is the status of unit $j$ at hour $h$ i.e. $U_{j}^{h}=0$ if unit $j$ is OFF at hour $h$ and $U_{j}^{h}=1$ if unit $j$ is ON at hour $h . \gamma_{j}$ is the start up cost coefficient for unit $j$ which is either the cold start cost $C S C_{j}$ if the duration unit $j$ has been $\mathrm{ON}$ is less than its cold start hour $C S h r_{j}$ or the hot start cost $H S C_{j}$ otherwise.

\subsection{Operational Constraints}

The GENCO operational constraints are given as:

(a) Power balance constraints

$$
\sum_{j=1}^{N} P_{j}^{h}=P_{s}^{h}+P_{b}^{h} \quad \forall h
$$


(b) Generation limit constraints

$$
U_{j}^{h} P_{j}^{\min } \leq U_{j}^{h} P_{j}^{h} \leq U_{j}^{h} P_{j}^{\max } \quad \forall i, \forall h
$$

(c) Generator ramp up constraints

$$
P_{j}^{h}-P_{j}^{h-1} \leq R U_{j} \quad \forall i, \forall h
$$

(d) Generator ramp down constraints

$$
P_{j}^{h-1}-P_{j}^{h} \leq R D_{j} \quad \forall i, \forall h
$$

(e) Generator minimum up time constraints

$$
U_{j}^{h}=1 \text { if } U_{j}^{t}-U_{j}^{t-1}=1, \quad \text { for } h=t, \ldots, t+M U T_{j}-1
$$

(f) Generator minimum down time constraints

$$
U_{j}^{h}=0 \text { if } U_{j}^{t-1}-U_{j}^{t}=1, \quad \text { for } h=t, \ldots, t+M D T_{j}-1
$$

In (15) and (16), $R U_{j}$ and $R D_{j}$ are the hour-to-hour ramp-up and ramp-down limits on unit $j$ respectively. In (17) and (18), $M U T_{j}$ and $M D T_{j}$ are the minimum-up-time and minimum-down-time limits on unit $j$ respectively.

Constraints (14) to (18) define unit operation limits and are similar to the formulation of a traditional utility's cost minimization UC problem [25]. Constraint (13) - the power balance constraint - states that the GENCO's total output at any given hour must equal its own load which is the sum of its expected spot market allocation $P_{s}^{h}$ and its bilateral market commitment $P_{b}^{h}$. While the bilateral market load would typically be agreed upon long in advance, the spot market allocation would depend on the GENCO's bidding strategy. A GENCO can predict the values of $P_{s}^{h}$ and $\alpha_{s}^{h}$ using its bidding strategy and the expected competitor bid curves. Generally, $P_{b}^{h}$ and $\alpha_{b}^{h}$ can be treated as constants while $P_{s}^{h}$ and $\alpha_{s}^{h}$ are variables dependent on the market dynamics. A GENCO would act in the day-ahead market to affect the values of $P_{s}^{h}$ and $\alpha_{s}^{h}$ so as to increase its profits.

A second significant difference between the formulations of the OBS-PBUC problem and the traditional UC problem is the absence of a minimum spinning reserve constraint [25] in the new formulation. This is because, supply of reserve, as well as other ancillary services, is not the responsibility of the GENCO. The ISO ensures the supply of such ancillary services by engaging the GENCOs. A GENCO thus gets payments for supply of both spinning and non-spinning reserve as given in the revenue equation (6). The adequacy of the reserve is ensured by the ISO by aggregating reserves from all GENCOs participating in the electricity market.

\section{OBS-PBUC SOLUTION METHODOLOGY}

In this section, the procedure adopted in this paper to solve the OBS-PBUC problem is outlined. Section 5.1. explains the procedure adopted to determine the profit corresponding to a given bidding strategy while section 5.2. details the step-by-step procedure implemented to select an optimal bidding strategy using the EPSO algorithm.

\subsection{Profit Maximization Procedure}

As illustrated in section 2., a GENCO can opt to bid high or bid low with respect to its marginal cost curve aiming to maximize its profits. Assume a linear reference marginal cost curve given by ${ }^{1}$ :

$$
M C^{\mathrm{ref}}=\rho+\beta P_{T}^{h},
$$

where $\rho$ and $\beta$ are the marginal cost curve coefficients for the GENCO and $P_{T}^{h}$ is its total output at hour $h$. Then, let $\mu^{h}$ be the bid curve multiplying factor at hour $h$ so that the GENCO bid curve at hour $h$ is given by:

$$
B C^{h}=\rho+\mu^{h} \beta P_{T}^{h} .
$$

The value of $\mu^{h}$ then defines the GENCO's bidding strategy at hour $h$. For a scheduling period of $H$ time periods, the set of bid factors $\mathcal{U}=\left\{\mu^{1}, \mu^{2}, \mu^{3}, \ldots, \mu^{H}\right\}$ constitutes the GENCO's bidding strategy.

\footnotetext{
${ }^{1}$ the subscript $i$ indicating the GENCO number is dropped to improve readability of the equations.
} 


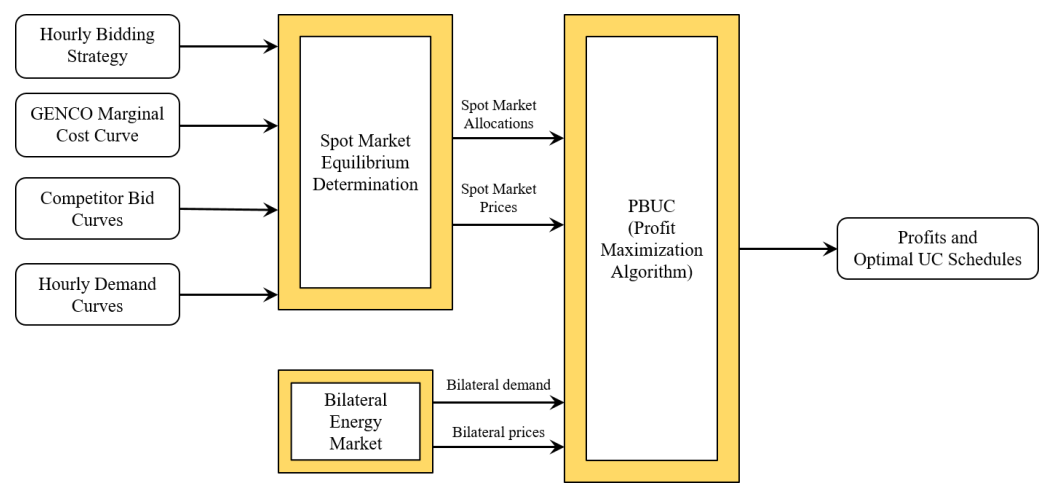

Figure 4. Profit Maximization procedure for a given bidding strategy.

For a given bidding strategy, the procedure used to determine a profit maximization schedule is shown in Figure 4. Given a particular bidding strategy, the reference marginal cost curve, forecasted competitor bid curves, and the hourly demand curves, the GENCO can forecast the market's supply and demand curves and hence the market equilibrium point as illustrated in section 2.. As seen from Figure 4, this gives the GENCO's spot market allocations and the MCPs (spot market prices). The spot market data is then combined with the bilateral market data (demand and prices) which is fed to a profit maximization algorithm to determine the optimal UC schedules and hence the profit associated with the bidding strategy $\mathcal{U}$.

\subsection{EPSO Algorithm}

Different bidding strategies give different spot market allocations and hence different optimal UC schedules. Thus, an algorithm that determines the optimal bidding strategy is implemented in this paper using the EPSO algorithm [18]. In the solution of the OBS-PBUC problem, a particle represents a candidate solution to the problem which in this case is a set of bid factors with one bid factor for each time period of the scheduling horizon. Given a scheduling period of $H$ hours, the $j^{t h}$ particle after $k$ iterations $\mathcal{U}_{j, k}=\left\{\mu_{j, k}^{1}, \mu_{j, k}^{2}, \mu_{j, k}^{3}, \ldots, \mu_{j, k}^{H}\right\}$ represents a position in the $H$-dimension solution space. The particle also has an associated velocity $V_{j, k}=$ $\left\{v_{j, k}^{1}, v_{j, k}^{2}, v_{j, k}^{3}, \ldots, v_{j, k}^{H}\right\}$ and an associated set of weights $W_{j, k}=\left\{w_{j, k}^{0}, w_{j, k}^{1}, w_{j, k}^{2}\right\}$. The velocity represents a direction in which the particle is moving in the solution space while the weights govern the direction of particle movement. $w_{j, k}^{0}$ governs the particle's inertia habit, $w_{j, k}^{1}$ governs its memory habit, while $w_{j, k}^{2}$ governs its cooperation habit [18].

A step by step outline of the procedure used to solve the OBS-PBUC problem using the EPSO algorithm follows.

\section{Step 1: Initialization:}

Randomly initialize $J$ particles $\mathcal{U}_{j, 0} \quad j=1,2, \ldots, J$. Each particle is a set of $H$ bid factors defining a particular bidding strategy. For each particle, an optimal unit commitment schedule is obtained using the profit maximization procedure shown in Figure 4. The obtained profit $P F_{j, 0}$ is the particle's initial fitness value. Each initialized particle is stored as $p$ Best $_{j}$; the corresponding fitness values as the best fitness values; and the fittest particle of all initialized particles as initial $g B e s t$.

Step 2: Set the algorithm generation counter $k=1$.

Step 3: Set the particles counter $j=1$.

Step 4: Replication

Each particle is replicated $R$ times i.e. $R$ new particles are created as:

$$
\mathcal{U}_{j, k}^{r}=\mathcal{U}_{j, k}, \quad r=1,2, \ldots R .
$$

Step 5: Set the particles replica counter $r=0$.

Step 6: Mutation

The weights for replica $r$ of particle $j$ are mutated as:

$$
w_{j, k+1}^{l, r}=w_{j, k}^{l, 0}+\tau_{w^{l}} N(0,1), \quad l=0,1,2 ;
$$

where $\tau_{w^{l}}$ is the standard deviation of the random mutation of weight parameter $w^{l}$. 
Step 7: Reproduction

A new offspring is generated according to the particle movement rule ${ }^{2}$ :

$$
\mathcal{U}_{j, k+1}^{r}=\mathcal{U}_{j, k}^{r}+V_{j, k+1}^{r}, \quad r=0,1,2, \ldots R,
$$

where

$$
V_{j, k+1}^{r}=w_{j, k}^{0, r} \cdot V_{j, k}^{r}+w_{j, k}^{1, r} \cdot\left(p B e s t_{j, k}-\mathcal{U}_{j, k}^{r}\right)+w_{j, k}^{2, r} \cdot\left(g B e s t_{k}^{*}-\mathcal{U}_{j, k}^{r}\right) .
$$

In (24), the $g$ Best $_{k}$ value is disturbed to give $g B e s t_{k}^{*}$ using:

$$
g B e s t_{k}^{*}=g \text { Best }_{k}+\tau_{g} N(0,1)
$$

where $\tau_{g}$ is the standard deviation of the random disturbance of the $g$ Best value.

Step 8: Fitness Evaluation

An optimal UC schedule is obtained using the procedure described by Figure 4. The profit obtained from the optimal UC schedule is is the offspring's fitness.

Step 9: Increase the replica counter by 1. If all replicas have been evaluated, go to Step 10, else go back to Step 6.

Step 10: Updating pBest

The fitness values of particle $j$ 's offspring are used to update the $p B e s t_{j, k}$.

Step 11: Selection

One offspring is chosen to survive to the next generation through a stochastic tournament. The stochastic tournament is carried out as follows:

- The fittest between the particle's offspring is determined.

- This particle survives to the next generation with a probability $p_{l u c k}$ while the other particles survive with a probability $\left(1-p_{\text {luck }}\right) / R$.

- If $p_{\text {luck }}$ is set to 1 then the best particle will always be chosen (pure elitism selection) while if $p_{\text {luck }}$ is set to $1 /(R+1)$, there will pure random selection.

Step 12: Increase the particle counter by 1. If all particles have been evaluated, go to Step 13, else go back to Step 4.

Step 13: Updating gBest

The original $g B e s t_{k-1}$ value and the highest profit from the $p B e s t_{j, k}$ values are used to update the $g B e s t_{k}$ value.

Step 14: Increase the algorithm generations counter by 1 . If $K$ generations have been exhausted, go to Step 15 , else go back to Step 3.

Step 15: Store gBest $_{K}$ and its corresponding UC schedule as the optimal solution and STOP.

\section{RESULTS AND DISCUSSION}

\subsection{Test System}

The IEEE 118-bus system data [26, 27] was used to simulate a deregulated electricity market environment with three GENCOs of different sizes in terms of installed capacity of generators. The three GENCOs operate several of the 54 thermal units in the IEEE 118-bus test system and the generating units data are given in Tables 3, 4, and 5 for GENCOs A, B, and C respectively. The generator cost coefficients are scaled up from the values given in [27] so as to give more realistic energy prices. Based on the installed capacity, GENCO A controls $60 \%$ (4340 MW out of $7220 \mathrm{MW}$ ) of the system capacity; GENCO B controls 30\% (2140 MW out of $7220 \mathrm{MW}$ ); while GENCO C controls $10 \%$ (740 MW out of $7220 \mathrm{MW}$ ) of the system capacity. The reference linear marginal cost curves for each of the three GENCOs and the aggregated system marginal cost curve are shown in Figure 5. The marginal cost curves show that GENCO A operates the cheaper units while GENCO C operates the most expensive units. Nominal market clearing prices $\alpha_{s}^{h}$ corresponding a spot market demand $P_{D}^{h}$ can be read off from the aggregated reference marginal cost curve of Figure 5(b). Additionally, linear demand curves are assumed for various load levels with a per-unit gradient of -5 i.e.

$$
\frac{\Delta \alpha_{s}^{h} / \alpha_{s}^{h}}{\Delta P_{T}^{h} / P_{T}^{h}}=-5 .
$$

\footnotetext{
${ }^{2} \mathcal{U}_{j, k}^{0}$ refers to the original particle while $\mathcal{U}_{j, k}^{1}, \mathcal{U}_{j, k}^{2}, \ldots$ refer to the replica particles.
} 
Equation (26) implies that a $100 \%$ increase in the spot market price would result in a $20 \%$ reduction in the spot market demand.

A 24-hour (day ahead) scheduling period is applied and the load level is shown in Figure 6. Apart from the allocations in the spot market, GENCO A is assumed to have a bilateral load demand equivalent to $10 \%$ of of the system spot market demand (Figure 6) at a constant price of $\$ 45 / \mathrm{MWh}$. A contract of differences factor $(\kappa$ in equation (7)) is set at 0.1 . GENCOs B and $\mathrm{C}$ are assumed to have no bilateral commitments. The price of reserve power (both spinning and non-spinning) is set at a constant $\$ 4.50 / \mathrm{MW}$.

Table 3. GENCO A's Generator Data

\begin{tabular}{|c|c|c|c|c|c|c|c|c|c|c|c|c|c|c|}
\hline $\begin{array}{r}\text { Unit } \\
\text { Code } \\
\end{array}$ & $\begin{array}{l}\text { No. of } \\
\text { Units }\end{array}$ & $\begin{array}{l}P_{i}^{\min } \\
{[\mathrm{MW}]}\end{array}$ & $\begin{array}{l}P_{i}^{\max } \\
{[\mathrm{MW}]}\end{array}$ & $\begin{array}{c}\text { Capacity } \\
{[\mathrm{MW}]}\end{array}$ & $\begin{array}{c}a \\
{[\$ / \mathrm{h}]}\end{array}$ & $\begin{array}{c}b \\
{[\$ / \mathrm{MWh}]}\end{array}$ & $\begin{array}{c}c \\
{\left[\$ / \mathrm{MWh}^{2}\right]}\end{array}$ & $\begin{array}{l}\text { MUT } \\
{[\mathrm{hrs}]}\end{array}$ & $\begin{array}{l}\text { MDT } \\
{[\mathrm{hrs}]}\end{array}$ & $\begin{array}{c}\mathrm{RU} \\
{[\mathrm{MW}]}\end{array}$ & $\begin{array}{c}\text { RD } \\
{[\mathrm{MW}]}\end{array}$ & $\begin{array}{l}\text { HSC } \\
{[\$ / h]}\end{array}$ & $\begin{array}{l}\text { CSC } \\
{[\$ / h]}\end{array}$ & $\begin{array}{l}\text { CShr } \\
\text { [hrs] }\end{array}$ \\
\hline A1 & 2 & 100 & 420 & 840 & 128.32 & 16.68 & 0.0212 & 10 & 10 & 210 & 210 & 250 & 500 & 20 \\
\hline $\mathrm{A} 2$ & 8 & 100 & 300 & 2400 & 13.56 & 25.78 & 0.0218 & 8 & 8 & 150 & 150 & 110 & 220 & 16 \\
\hline A3 & 2 & 50 & 250 & 500 & 56.00 & 24.66 & 0.0048 & 8 & 8 & 125 & 125 & 100 & 200 & 16 \\
\hline $\mathrm{A} 4$ & 1 & 50 & 200 & 200 & 13.56 & 25.78 & 0.0218 & 8 & 8 & 100 & 100 & 400 & 800 & 16 \\
\hline A5 & 3 & 25 & 100 & 300 & 20.30 & 35.64 & 0.0256 & 5 & 5 & 50 & 50 & 50 & 100 & 10 \\
\hline A6 & 2 & 25 & 50 & 100 & 117.62 & 45.88 & 0.0195 & 2 & 2 & 25 & 25 & 45 & 90 & 4 \\
\hline Total & 18 & & & 4340 & & & & & & & & & & \\
\hline
\end{tabular}

Table 4. GENCO B's Generator Data

\begin{tabular}{|c|c|c|c|c|c|c|c|c|c|c|c|c|c|c|}
\hline $\begin{array}{c}\text { Unit } \\
\text { Code }\end{array}$ & $\begin{array}{c}\text { No. of } \\
\text { Units }\end{array}$ & $\begin{array}{l}P_{i}^{\min } \\
{[\mathrm{MW}]}\end{array}$ & $\begin{array}{l}P_{i}^{\max } \\
{[\mathrm{MW}]}\end{array}$ & $\begin{array}{c}\text { Capacity } \\
{[\mathrm{MW}]}\end{array}$ & $\begin{array}{c}a \\
{[\$ / h]}\end{array}$ & $\begin{array}{c}b \\
{[\$ / \mathrm{MWh}]}\end{array}$ & $\begin{array}{c}c \\
{\left[\$ / \mathrm{MWh}^{2}\right]}\end{array}$ & $\begin{array}{l}\text { MUT } \\
{[\mathrm{hrs}]}\end{array}$ & $\begin{array}{l}\text { MDT } \\
{[\mathrm{hrs}]}\end{array}$ & $\begin{array}{c}\mathrm{RU} \\
{[\mathrm{MW}]}\end{array}$ & $\begin{array}{c}\mathrm{RD} \\
{[\mathrm{MW}]}\end{array}$ & $\begin{array}{l}\mathrm{HSC} \\
{[\$ / \mathrm{h}]}\end{array}$ & $\begin{array}{l}\mathrm{CSC} \\
{[\$ / \mathrm{h}]}\end{array}$ & $\begin{array}{l}\text { CShr } \\
\text { [hrs] }\end{array}$ \\
\hline B1 & 1 & 100 & 350 & 350 & 65.92 & 21.50 & 0.0060 & 8 & 8 & 175 & 175 & 100 & 200 & 16 \\
\hline B2 & 1 & 100 & 300 & 300 & 65.92 & 21.50 & 0.0060 & 8 & 8 & 150 & 150 & 440 & 880 & 16 \\
\hline B3 & 2 & 50 & 200 & 400 & 78.00 & 26.58 & 0.0088 & 8 & 8 & 100 & 100 & 100 & 200 & 16 \\
\hline B4 & 8 & 25 & 100 & 800 & 20.30 & 35.64 & 0.0256 & 5 & 5 & 50 & 50 & 50 & 100 & 10 \\
\hline B5 & 1 & 20 & 50 & 50 & 117.62 & 45.88 & 0.0195 & 2 & 2 & 25 & 25 & 45 & 90 & 4 \\
\hline B6 & 8 & 5 & 30 & 240 & 63.34 & 52.49 & 0.1393 & 1 & 1 & 15 & 15 & 40 & 80 & 2 \\
\hline
\end{tabular}

Table 5. GENCO C's Generator Data

\begin{tabular}{|c|c|c|c|c|c|c|c|c|c|c|c|c|c|c|}
\hline $\begin{array}{l}\text { Unit } \\
\text { Code }\end{array}$ & $\begin{array}{l}\text { No. of } \\
\text { Units }\end{array}$ & $\begin{array}{l}P_{i}^{\min } \\
{[\mathrm{MW}]}\end{array}$ & $\begin{array}{l}P_{i}^{\max } \\
{[\mathrm{MW}]}\end{array}$ & $\begin{array}{c}\text { Capacity } \\
{[\mathrm{MW}]}\end{array}$ & $\begin{array}{c}a \\
{[\$ / \mathrm{h}]}\end{array}$ & $\begin{array}{c}b \\
\text { [\$/MWh] }\end{array}$ & $\begin{array}{c}c \\
{\left[\$ / \mathrm{MWh}^{2}\right]}\end{array}$ & $\begin{array}{l}\text { MUT } \\
{[\mathrm{hrs}]}\end{array}$ & $\begin{array}{l}\text { MDT } \\
{[\mathrm{hrs}]}\end{array}$ & $\begin{array}{c}\mathrm{RU} \\
{[\mathrm{MW}]}\end{array}$ & $\begin{array}{c}\mathrm{RD} \\
{[\mathrm{MW}]}\end{array}$ & $\begin{array}{l}\mathrm{HSC} \\
{[\$ / \mathrm{h}]}\end{array}$ & $\begin{array}{l}\mathrm{CSC} \\
{[\$ / \mathrm{h}]}\end{array}$ & $\begin{array}{l}\text { CShr } \\
{[\mathrm{hrs}]}\end{array}$ \\
\hline $\mathrm{C} 1$ & 4 & 25 & 100 & 400 & 20.30 & 35.64 & 0.0256 & 5 & 5 & 50 & 50 & 50 & 100 & 10 \\
\hline $\mathrm{C} 2$ & 1 & 30 & 80 & 80 & 48.66 & 30.94 & 0.0918 & 3 & 3 & 40 & 40 & 45 & 90 & 6 \\
\hline C 3 & 6 & 5 & 30 & 180 & 63.34 & 52.49 & 0.1393 & 1 & 1 & 15 & 15 & 40 & 80 & 2 \\
\hline $\mathrm{C} 4$ & 4 & 5 & 20 & 80 & 35.90 & 75.39 & 0.0566 & 1 & 1 & 10 & 10 & 30 & 60 & 2 \\
\hline Total & 15 & & & 740 & & & & & & & & & & \\
\hline
\end{tabular}

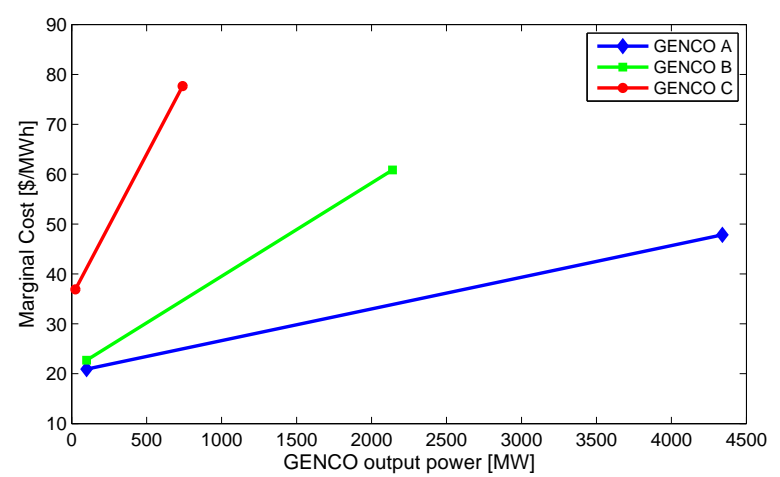

(a)

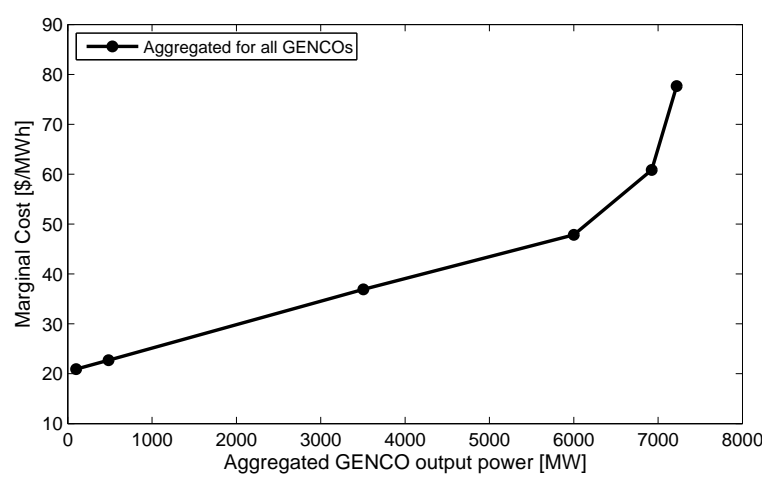

(b)

Figure 5. (a) Individual marginal cost curves for the three GENCOs and (b) aggregated system marginal cost curve.

First, in section 6.2. a discussion of the nominal system equilibrium is presented i.e. the market prices, spot market load allocations, and expected GENCO profits (results of the PBUC) if each GENCO were to bid its 


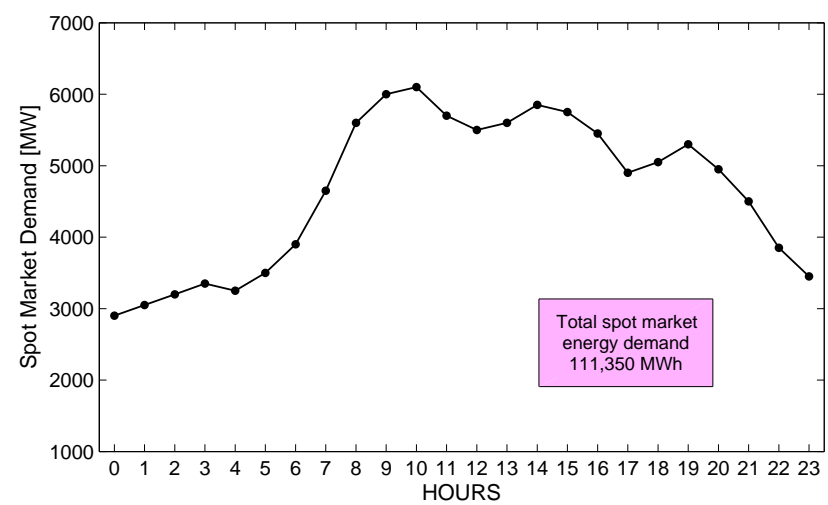

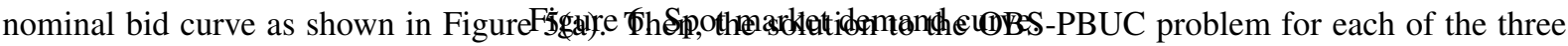
GENCOs using the proposed EPSO algorithm is presented in section 6.3.. Finally, in section 6.4., a comparison of the simulations results using the proposed EPSO algorithm and the classical PSO algorithm is presented.

\subsection{Nominal System Equilibrium}

The spot market demand curve plotted in Figure 6 shows the load varying from a low of 2900 MW at midnight to a maximum of $6100 \mathrm{MW}$ at $10 \mathrm{AM}$. If all three GENCOs bid their reference marginal cost curves, the hourly market clearing prices (MCPs) will be as shown in Figure 7(a). As expected, the MCP curve follows the spot market load with a minimum value of $\$ 34.17 / \mathrm{MWh}$ at midnight and a peak of $\$ 57.82 / \mathrm{MWh} 10 \mathrm{AM}$. Also shown in Figure 7(b) is the hourly allocation of the spot market load to the three GENCOs. Figure 7(b) shows that GENCO A gets most of the load and is actually limited during the peak hours of 8 AM to 4 PM by its capacity less the bilateral market demand. GENCO B supplies mainly the intermediate load with the allocation of 1978 MW at 10 AM almost equaling its capacity of 2140 MW. GENCO C primarily acts as a peak load generator only supplying energy during the peak hours. During the low peak hours before 5 AM, GENCO C receives no allocation thus only receiving payments from sale of reserve power.

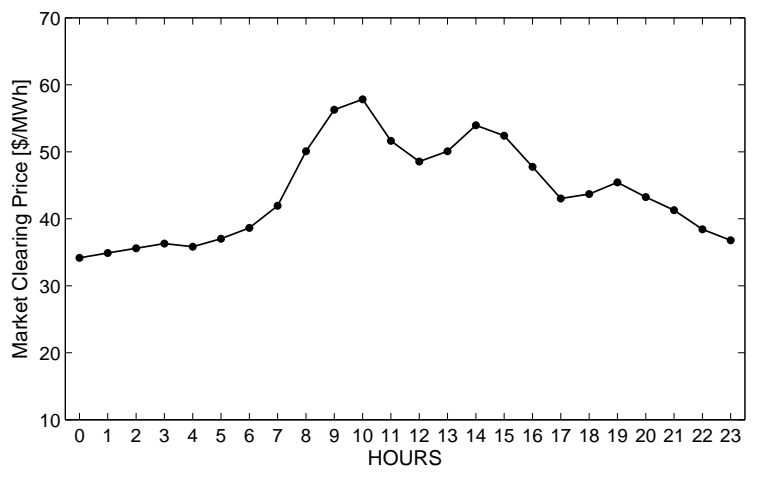

(a)

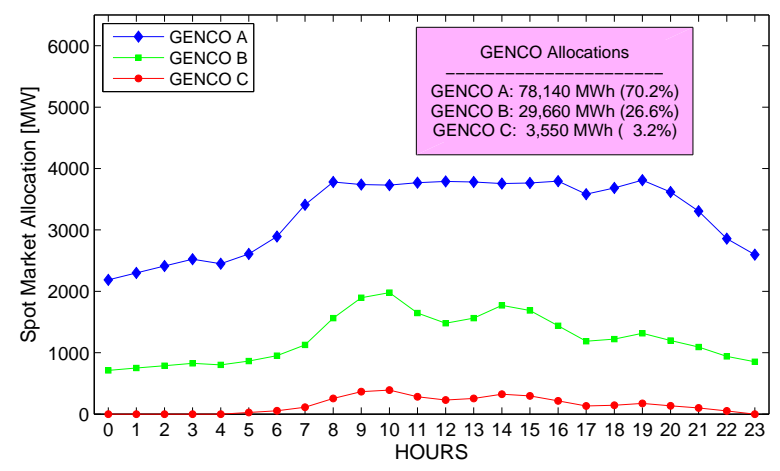

(b)

Figure 7. (a) Hourly MCPs corresponding to the nominal marginal cost curves and (b) spot market allocations for each individual GENCO.

Also shown in Figure 7(b) is the total daily energy to be supplied by the three GENCOs in the spot market. it is observed that GENCO A is allocated $70.2 \%$ of the spot market demand during the day while GENCOs B and $\mathrm{C}$ are allocated only $26.6 \%$ and $3.2 \%$ respectively. While GENCO B's allocation compares relatively well to its installed capacity ( $30 \%$ relative to the system capacity) GENCO A's allocation is significantly higher than its relative installed capacity while GENCO C's allocation is significantly lower than its relative installed capacity. Again, this is because GENCO A has cheaper units hence is usually allocated first while GENCO C has more expensive units and is allocated last. A Profit Based Unit Commitment algorithm was run for each of the three GENCOs with the base case spot market allocations shown in Figure 7(b) and the the expected values of daily revenue, operating costs, and profits for each GENCO are shown in Table 6. 
Table 6. Revenues, costs, and profits for nominal bidding strategies.

\begin{tabular}{lrrr}
\hline & GENCO A & GENCO B & GENCO C \\
\hline REVENUES & & & \\
Spot Market & $3,523,184$ & $1,369,344$ & 177,640 \\
Reserve Sales & 59,434 & 86,817 & 56,838 \\
Bilateral Market & 501,075 & - & - \\
CFDs & 2,922 & - & - \\
\hline TOTAL REVENUE & $4,086,615$ & $1,456,161$ & 234,479 \\
TOTAL COST & $2,620,007$ & 914,826 & 148,268 \\
\hline PROFIT & $1,466,608$ & 541,335 & 86,211 \\
\hline \hline
\end{tabular}

\subsection{Optimal Bidding Strategy}

The OBS-PBUC problem was solved using the EPSO algorithm described in section 5.2. for each of the three GENCOs assuming that each is acting independently and using the competing GENCO's nominal marginal cost curves as the expected competitor bidding curves in each case. Values for the various parameters used in the EPSO algorithm are given in Table 7. Simulation results including the optimal values of the hourly bid factors, the expected MCPs, spot market allocations, revenues, costs, and profits are discussed next.

Table 7. Parameter values for EPSO algorithm.

\begin{tabular}{lc}
\hline Parameter & Value \\
\hline no. of particles & 20 \\
no. of iterations & 500 \\
initial value of weight $w^{0}$ & 0.4 \\
initial value of weight $w^{1}$ & 1.0 \\
initial value of weight $w^{2}$ & 2.0 \\
standard deviation of weights, $\tau_{w^{l}}$ & 0.1 \\
standard deviation of gBest, $\tau_{g}$ & 0.01 \\
no. of replica particles & 1 \\
probability of best particle surviving, $p_{l u c k}$ & 0.8 \\
\hline
\end{tabular}

The hourly values of the bid factors that give the maximum profits defines a GENCO's optimal bidding strategy. Figure 8 shows the obtained values of the optimal bid strategies for the three GENCOs. As seen from Figure 8 , the optimal values of the hourly bidding factors are in the range of 2.0 to 4.3 for GENCO A, 0.9 to 1.8 for GENCO B, and 0.5 to 1.3 for GENCO C. The interpretation here is that GENCO A should generally bid higher than its nominal bidding curve, GENCO B should bid just slightly higher than its nominal bidding curve while GENCO C should bid lower than its nominal bidding curve in order to maximize their respective profits.

Figures 9 (a), (b), and (c) show how the optimal bidding strategy for each GENCO would alter the hourly spot market clearing prices. GENCO A's high bidding factors significantly raise the MCPs; GENCO B's strategy would slightly raise the MCPs while GENCO C's strategy has almost no effect on the MCPs. These results confirm that GENCO C is in fact a price taker while GENCO A is a price maker with significant market power to alter the MCPs. The effect of the optimal bidding strategies on the spot market allocations are shown in Figures 9 (d), (e), and (f). GENCO A's optimal bidding strategy would significantly reduce its allocation in the spot market; GENCO B's optimal bidding strategy would slightly reduce its allocation in the spot market; while GENCO C's optimal bidding strategy would significantly increase its allocation in the spot market during peak hours.

Comparisons of the revenues, costs, and profits for each of the three GENCO's are given in Tables 8, 9, and 10. Table 8 - corresponding to GENCO A - shows a reduction in the revenues from the spot market 


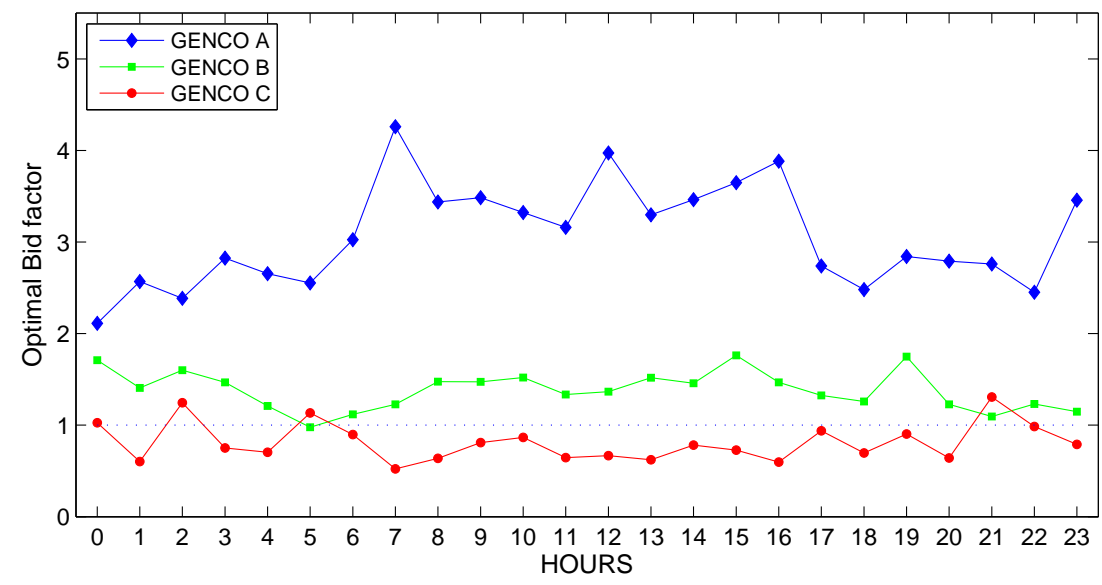

Figure 8. Optimal hourly bid factors.

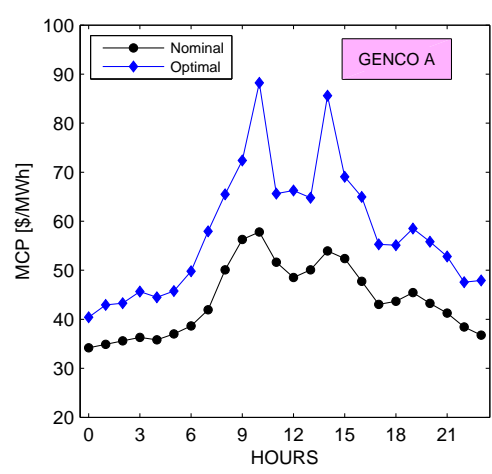

(a)

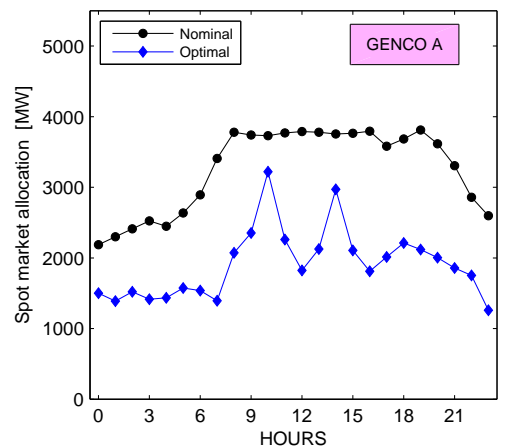

(d)

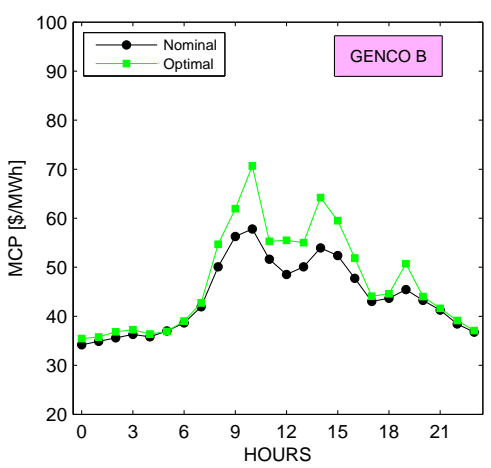

(b)

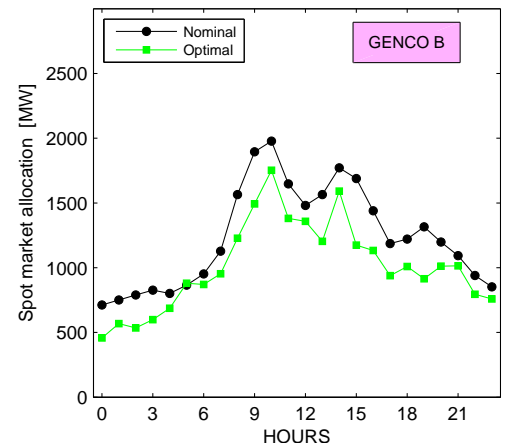

(e)

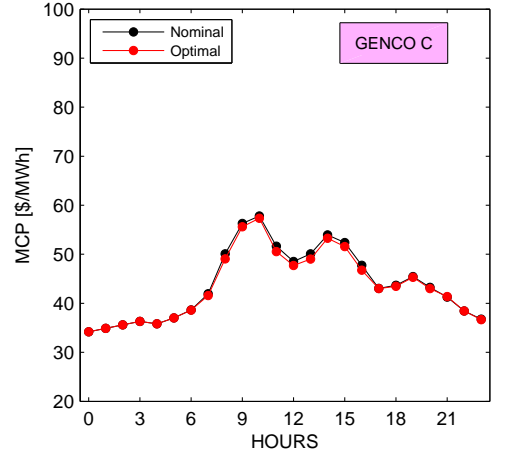

(c)

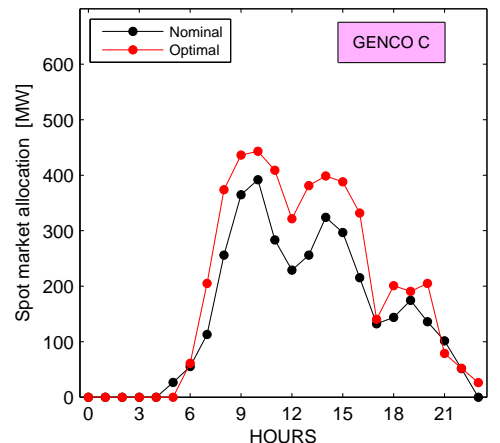

(f)

Figure 9. Effect of individual GENCO optimal bidding strategies on the MCPs and the spot market allocations.

resulting from the reduced allocations due to the optimal bidding strategy. However the reduction in operating costs coupled with revenues from the increased reserve sales and CFDs gives an overall increase in profits. These results show that it is more beneficial for GENCO A to bid high to increase the MCPs even though this may reduce its spot market allocations and its spot market revenues as a result.

Table 9 - corresponding to GENCO B - shows similar results to those of GENCO A though to a lesser extent. The reduction in operating costs coupled with revenues from the increased reserve sales outweighs reduction in spot market revenues resulting from the reduced allocations due to the optimal bidding strategy. However, GENCO B achieves only a $13.3 \%$ increase in profits compared to a $38.1 \%$ increase for GENCO A. This is a consequence of the GENCO A's market power enabling it to have a greater influence on the MCPs a result that is also deduced from Figures 9 (a) and (b).

Table 10 - corresponding to GENCO C — shows that for the smallest GENCO the optimal bidding 
Table 8. GENCO A revenues, costs, and profits for optimal bidding strategy.

\begin{tabular}{lrrr}
\hline & Nominal & Optimal & Difference \\
\hline REVENUES & & & \\
Spot Market & $3,523,184$ & $2,768,844$ & $-754,340$ \\
Reserve Sales & 59,434 & 189,213 & $+129,779$ \\
Bilateral Market & 501,075 & 501,075 & 0 \\
CFDs & 2,922 & 85,562 & $+82,640$ \\
\hline Total Revenues & $4,086,615$ & $3,544,694$ & $-541,921$ \\
Total Costs & $2,620,007$ & $1,518,954$ & $-1,101,053$ \\
\hline Profits [\$/day] & $1,466,608$ & $2,025,739$ & $+559,131$ \\
& & & $(+38.1 \%)$ \\
\hline \hline
\end{tabular}

Table 9. GENCO B revenues, costs, and profits for optimal bidding strategy.

\begin{tabular}{lrrr}
\hline & Nominal & Optimal & Difference \\
\hline REVENUES & & & \\
Spot Market & $1,369,344$ & $1,221,779$ & $-147,565$ \\
Reserve Sales & 86,817 & 108,219 & $+21,402$ \\
Bilateral Market & - & - & - \\
CFDs & - & - & - \\
\hline Total Revenues & $1,456,161$ & $1,329,998$ & $-126,163$ \\
Total Costs & 914,826 & 716,916 & $-197,910$ \\
\hline Profits [\$/day] & 541,335 & 613,082 & 71,747 \\
& & & $(+13.3 \%)$ \\
\hline \hline
\end{tabular}

strategy is to bid low in order to capture slightly more of the spot market demand. As seen from Table 10, the net increase in revenues (increase in spot market revenues less reductions in reserve sales) is greater than the increase in operating costs for supplying more energy. However, the final increase in profits $(+3.7 \%)$ is relatively small when compared to the profit increases realized by GENCOs A and B. Again this is attributed to GENCO C's relative weakness in the electricity market.

Table 10. GENCO C revenues, costs, and profits for optimal bidding strategy.

\begin{tabular}{lrrr}
\hline & Nominal & Optimal & Difference \\
\hline REVENUES & & & \\
Spot Market & 177,640 & 228,785 & 51,145 \\
Reserve Sales & 56,838 & 52,467 & $-4,371$ \\
Bilateral Market & - & - & - \\
CFDs & - & - & - \\
\hline Total Revenues & 234,479 & 281,252 & 46,773 \\
Total Costs & 148,268 & 191,856 & 43,588 \\
\hline Profits [\$/day] & 86,211 & 89,396 & 3,185 \\
& & & $(+3.7 \%)$ \\
\hline \hline
\end{tabular}


The relationship between the GENCO market power (measured by the GENCO's relative size in the market) and the effect of their optimal bidding strategies on the market dynamics are summarized in Table 11.

Table 11. Effect of GENCO market power on market prices, allocations, and individual profits.

\begin{tabular}{lccc}
\hline & GENCO A & GENCO B & GENCO C \\
\hline $\begin{array}{l}\text { \% installed capacity } \\
\text { (market power) }\end{array}$ & $60 \%$ & $30 \%$ & $10 \%$ \\
\hline $\begin{array}{l}\text { Average \% change in spot energy } \\
\text { market prices }\end{array}$ & $+31.4 \%$ & $+7.2 \%$ & $-0.8 \%$ \\
$\begin{array}{l}\text { Average \% change in spot energy } \\
\text { market allocations }\end{array}$ & $-41.5 \%$ & $-18.1 \%$ & $+30.8 \%$ \\
$\%$ change in expected profits & $+38.1 \%$ & $+13.3 \%$ & $+3.7 \%$ \\
\hline
\end{tabular}

\subsection{Comparison of EPSO and PSO algorithms}

The performance of the EPSO algorithm implemented in this paper was compared to the performance of a similar implementation using the classical PSO algorithm. The problem was solved for the three GENCOs 20 times using both algorithms starting from the same initial particles in each trial. The same parameter values (i.e. number of particles, number of iterations, and weight values) given in Table 12 for the EPSO algorithm were used for the implemented PSO algorithm. The performance of the two algorithms was measured in terms of the objective function values from the 20 runs. Table 12 gives the best, average, and worst solutions obtained for both algorithms for each of the three GENCOs. Also given in Table 12 is the standard deviation for the solutions. The table shows that the proposed EPSO algorithm outperforms the classical PSO algorithm in all cases. The superior performance of the EPSO algorithm is attributed to the mutation characteristics embedded in the algorithm which tune the algorithm parameters in subsequent generations hence resulting in a better search of the solution space.

Table 12. Comparison of solution quality using PSO and EPSO algorithms.

\begin{tabular}{|c|c|c|c|c|c|c|}
\hline & \multicolumn{2}{|c|}{ GENCO A } & \multicolumn{2}{|c|}{ GENCO B } & \multicolumn{2}{|c|}{ GENCO C } \\
\hline & PSO & EPSO & PSO & EPSO & PSO & EPSO \\
\hline Best solution $[\$ /$ day $]$ & $1,954,488$ & $2,025,739$ & 610,497 & 613,082 & 88,703 & 89,396 \\
\hline Average solution $[\$ /$ day $]$ & $1,903,261$ & $1,967,363$ & 598,663 & 600,745 & 87,987 & 88,982 \\
\hline Worst solution $[\$ /$ day $]$ & $1,850,798$ & $1,931,389$ & 584,485 & 585,105 & 87,293 & 88,482 \\
\hline Standard deviation $[\$ /$ day $]$ & 40,644 & 31,811 & 7,348 & 6,365 & 348 & 262 \\
\hline
\end{tabular}

\section{CONCLUSION}

This paper presents a methodology for determining an optimal bidding strategy and unit commitment for a GENCO operating in a competitive electricity market place. The proposed procedure seeks to determine how a GENCO should structure its hourly bid curves so as to maximize profits where profit is calculated as the difference between expected revenues and generation costs for expected GENCO own demand. GENCO demand is determined as the sum of allocations from the spot market and bilateral market commitments. The complex optimization problem is solved using an evolutionary particle swarm optimization (EPSO) technique. Numerical results from simulations of a typical system with three GENCOs of different sizes confirms the effectiveness of the proposed algorithm. Generally, it is shown that large GENCOs with significant market power could raise their bids - thereby significantly raising electricity prices - and hence increasing their profits; though the higher bids could reduce their allocations in the spot market. Smaller GENCOs with less market power are generally price takers and have relatively less influence on the market equilibrium. The optimization algorithm results in only slight increases in expected profits for these GENCOs. Finally, a comparison of solution quality from the proposed EPSO algorithm with those obtained using the classic PSO algorithm shows that the proposed methodology performs much better. 


\section{REFERENCES}

[1] B. Saravanan, S. Das, S. Sikri, and D. P. Kothari, "A solution to the unit commitment problem - a review," Frontiers in Energy, vol. 7, no. 2, pp. 223-236, 2013.

[2] M. S. Javadi, "Security constraint unit commitment considering line and unit contingencies-particle swarm optimization," International Journal of Applied Power Engineering, vol. 1, no. 1, pp. 13-20, 2012.

[3] S. S. Sakthi, R. K. Santhi, N. M. Krishnan, S. Ganesan, and S. Subramanian, "Wind integrated thermal unit commitment solution using grey wolf optimizer," International Journal of Electrical and Computer Engineering, vol. 7, no. 5, pp. 2309-2320, 2017.

[4] E. Delarue, D. Cattrysse, and W. Dhaeseleer, "Enhanced priority list unit commitment method for power systems with a high share of renewables," Electric Power Systems Research, vol. 105, no. 0, pp. 115 - 123 , 2013.

[5] K. Choudhary, R. Kumar, D. Upadhyay, and B. Singh, "Optimal power flow based economic generation scheduling in day-ahead power market," International Journal of Applied Power Engineering, vol. 6, no. 3, pp. 124-134, 2017.

[6] L. Philipson and H. L. Willis, Understanding Electric Utilities and De-Regulation, 2nd ed. Florida, USA: Taylor \& Francis Group, 2006.

[7] K. Asokan and R. Ashokkumar, "A simple approach for optimal generation scheduling to maximize gencos profit using ppd table and abc algorithm under deregulated environment," International Journal of Electrical and Computer Engineering, vol. 2, no. 1, pp. 137-146, 2012.

[8] T. Li and M. Shahidehpour, "Price-based unit commitment: a case of Lagrangian relaxation versus mixed integer programming," Power Systems, IEEE Transactions on, vol. 20, no. 4, pp. 2015-2025, Nov 2005.

[9] R. H. Kwon and D. Frances, Handbook of Networks in Power Systems I. Springer Berlin Heidelberg, 2012, ch. Optimization-based bidding in day-ahead electricity auction markets: A review of models for power producers, pp. 41-59.

[10] M. M. Belsnes, G. Warland, and O. Wolfgang, "Simulating equilibrium prices in oligopoly power markets," in 2011 IEEE Trondheim PowerTech, June 2011, pp. 1-8.

[11] A. Rajan, C. Christober, P. Sundarajan, V. Jamuna, R. Madhusubash, and B. Udayakumar, "Multi-area unit commitment in deregulated electricity market using DP approach," Inter. Journal on Recent Trends in Engineering and Technology, vol. 3, no. 3, pp. 210-213, May 2010.

[12] E. Delarue, P. V. D. Bosch, and W. Dhaeseleer, "Effect of the accuracy of price forecasting on profit in a price based unit commitment," Electric Power Systems Research, vol. 80, no. 10, pp. 1306 - 1313, 2010.

[13] J. Raglend, C. Raghuveer, G. R. Avinash, N. Padhy, and D. Kothari, "Solution to profit based unit commitment problem using particle swarm optimization," Applied Soft Computing, vol. 10, no. 4, pp. 1247-1256, Sept. 2010.

[14] H. S. Madraswala and A. S. Deshpande, "Genetic algorithm solution to unit commitment problem," in 2016 IEEE 1st International Conference on Power Electronics, Intelligent Control and Energy Systems (ICPEICES), July 2016, pp. 1-6.

[15] T. Venkatesana and M. Sanavullahb, "SFLA approach to solve PBUC problem with emission limitation," International Journal of Electrical Power and Energy Systems, vol. 46, pp. 1-9, March 2013.

[16] A. Sudhakar, C. Karri, and A. J. Laxmi, "Profit based unit commitment for GENCOs using lagrange relaxation - differential evolution," Engineering Science and Technology, an International Journal, pp. -, 2016.

[17] S. Selvi, M. Moses, and C. Rajan, "LR-EP approach for solving profit based unit commitment problem with losses in deregulated markets," Przeglad Elektrotechniczny, vol. 11, pp. 210-213, 2013.

[18] V. Miranda and N. Fonseca, "EPSO-evolutionary particle swarm optimization, a new algorithm with applications in power systems," in IEEE/PES Transmission and Distribution Conference and Exhibition, vol. 2, Oct 2002, pp. 745-750 vol.2.

[19] V. Miranda and N. W. Oo, "New experiments with epso evolutionary particle swarm optimization," in IEEE Swarm Intelligence Symposium 2006, Indianapolis (IN), USA, 2006, pp. 1-8.

[20] J. Jamian, M. Mustafa, H. Mokhlis, and M. Baharudin, "Implementation of evolutionary particle swarm optimization in distributed generation sizing," International Journal of Applied Power Engineering, vol. 2, no. 3, pp. 125-140, 2013.

[21] M. Shahidehpour and M. Alomoush, Restructured Electrical Power Systems, Operation, Trading, and Volatility, 1st ed. New York: Marcel Decker, 2000.

[22] V. Miranda, H. Keko, and A. Jaramillo, Advances in Evolutionary Computing for System Design, Studies in Computational Intelligence. Springer Berlin Heidelberg, 2007, vol. 66, ch. EPSO: Evolutionary Particle Swarms, pp. 139-168. 
[23] J. Kennedy and R. Eberhart, "Particle swarm optimization," in Neural Networks, 1995. Proceedings., IEEE International Conference on, vol. 4, Nov 1995, pp. 1942-1948 vol.4.

[24] X. Ma, D. I. Sun, and K. W. Cheung, "Evolution toward standardized market design," IEEE Transactions on Power Systems, vol. 18, no. 2, pp. 460-469, May 2003.

[25] J. Lin and F. H. Magnago, Electricity Markets:Theories and Applications. Wiley-IEEE Press, $2017, \mathrm{ch}$. Power System Unit Commitment, pp. 97-118.

[26] University of Washington. (2017, October) Power system test case archive. [Online]. Available: http://www.ee.washington.edu/research/pstca/.

[27] Illinois Institute of Technology. (2017, October) PBUC Data. [Online]. Available: http://motor.ece.iit.edu/data/PBUCData.pdf. 